\title{
MODELOS DIDÁTICOS COMO ESTRATEGIA INVESTIGATIVA E COLABORATIVA PARA 0 ENSINO DE BOTÂNICA
}

\author{
DIDACTIC MODELS AS AN INVESTIGATIVE AND COLLABORATIVE STRATEGY \\ FOR BOTANICAL EDUCATION
MODELOS DIDÁCTICOS COMO ESTRATEGIA INVESTIGATIVA Y COLABORATIVA PARA LA ENSEÑANZA DE BOTÁNICA

Viviana Borges Corte

viviana.borges@gmail.com

Fernanda Guimarães Saraiva nandagsbr@gmail.com

Idalina Tereza de Almeida Leite Perin

ida21.perin@gmail.com

REVISTA PEDAGÓGICA

Revista do Programa de Pós-graduação em Educação da Unochapecó | ISSN 1984-1566

Universidade Comunitária da Região de Chapecó | Chapecó-SC, Brasil Como referenciar este artigo: CORTE, V. B.; SARAIVA, F. G.; PERIN, I. T. A. L. Modelos didáticos como estratégia investigativa e colaborativa para o ensino de botânica. Revista Pedagógica, Chapecó, v. 20, n. 44, p. 172-196, mai./ago. DOI: http://dx.doi.org/10.22196/rp.v20i44.3871

RESUMO: A desmotivação dos alunos é frequentemente tida pelos professores de Biologia como causa do insucesso escolar. Para superar tal dificuldade, um projeto de pesquisa foi realizado, liderado pelos estudantes de uma escola pública de ensino médio no município de VitóriaES. Em atividade investigativa acerca das principais dificuldades na aprendizagem de biologia, os conceitos de Botânica mostraram-se prioritários. Modelos didáticos para aulas de botânica foram elaborados pelos alunos de forma coletiva e colaborativa, e utilizados em aulas mais tarde, com o objetivo de tornar as aulas mais interessantes. Uma avaliação dos modelos foi realizada pelos professores de biologia e pelos alunos. A utilização dos modelos didáticos e a liderança dos alunos autores do projeto, mostram-se importantes estratégias motivadora, tendo tornado as aulas mais participativas, as relações mais horizontais entre alunos e professores e, assim, facilitou a aprendizagem de conceitos relacionados à botânica entre muitas outras habilidades.

Palavras-Chave: Ensino de Botânica, motivação, método investigativo, aprendizagem colaborativa

ABSTRACT: The demotivation of students is often considered by biology teachers as a cause of school failure. In order to overcome this difficulty, a research project was carried out, led by the students of a public high school in the municipality of Vitória-ES. An investigative activity on the main difficulties in learning biology was conducted and showed the concepts of botany as priorities. The students then produced didactic models for botany classes, acting in a collective and collaborative way, and later applied them in classes, with the aim to make the latter more interesting. The biology teachers and the students then performed an evaluation of the models in the classes. As a result, the use of didactic models and the leadership of the students authors of the project, has shown to be an important motivating factor and have not only enhanced student participation in the classes but also made the relationships between students and teacher more horizontal and, thus, eased the learning of concepts related to botany, among many other skills.

Keywords: Teaching Botany, motivation, investigative method, collaborative learning

RESUMEN: La desmotivación de los alumnos es frecuentemente tenida por los profesores de Biología como causa del fracaso en la escola. Para superponer tal dificultad, un proyecto de investigación fue realizado, liderado por los estudiantes de una escuela pública de enseñanza media en el municipio de Vitória-ES. En actividad investigativa acerca de las principales dificultades en el aprendizaje de biología, los conceptos de Botánica se mostraron prioritarios. Los modelos didácticos para clases de botánica fueron elaborados por los alumnos de forma colectiva y colaborativa, y aplicados en clases más tarde, con el objetivo de hacer las clases más interesantes. Una evaluación de los modelos fue realizada por los profesores de biología y los alumnos. El uso de los modelos fue evaluado por los profesores de biología y los alumnos de las clases. La utilización de los modelos didácticos y el liderazgo de los alumnos autores del proyecto, se mostró una importante estrategia motivadora, habiendo convertido las clases más participativas, las relaciones más horizontales entre estudiantes y profesores y, así, facilitó el aprendizaje de conceptos relacionados a la botánica entre muchas otras habilidades.

Palabras-Claves: Enseñanza de Botánica, motivación, método investigativo, aprendizaje colaborativo 


\section{INTRODUÇÃO}

Usualmente, o ensino é focado no modelo tradicional, em que o docente explica o conteúdo verbalmente e espera que os alunos memorizem o que foi dito e reproduzam nas avaliações (HOBSBAUM et al. 1996; STOFFLETT, 1999; RESCHKE, 2009). Este método de ensino vertical de transmissão do conhecimento do professor para o aluno, faz com que a aprendizagem se processe de forma mecânica, em que o este não é solicitado a pensar e nem a desenvolver seu pensamento independente e criativo (NEVES et al. 2010). Esse método promove o distanciamento e dissociação do conteúdo em relação a vida cotidiana, causando desinteresse por parte dos alunos e desfavorecendo o processo de aprendizagem (LONGO, 2012).

Tal estrutura educacional engessada em moldes arcaicos não condiz com as demandas da sociedade em que vivemos e traz sérias limitações para a formação dos estudantes. Tendo como premissa uma educação para a vida, que possibilite a formação de cidadãos críticos, pensantes de seus atos e responsáveis socialmente, nós educadores sabemos que precisamos ir além e fazer com que os alunos estabeleçam vínculos de afetividade com a escola e não que a frequentem por obrigação. Assim, fazer com que a aprendizagem estabeleça sentido para os estudantes e promova a transformação desses sujeitos é a meta a ser alcançada.

Para tanto é fundamental o engajamento do aluno como agente ativo nas atividades escolares, ou seja, a atividade de aprendizagem deve ser estabelecida em uma parceria professor-aluno, e não de forma unilateral, na qual, muitas vezes, o professor parece estar mais preocupado com a aprendizagem do aluno do que ele próprio.

\section{ADESMOTIVAÇÃONOENSINO DE BOTÂNICA}

Diante do desinteresse dos alunos quanto ao ensino-aprendizagem de biologia, uma das grandes dificuldades - senão a maior - é quanto aos conteúdos de botânica (BRANCO et al. 2015), pois há, de modo geral, grande rejeição por parte dos alunos e também dos professores. Diversos autores corroboram e referenciam o desinteresse por tais conteúdos e as justificativas constituem um sistema cíclico que retroalimenta a desmotivação de estudantes e professores, como demonstrado na Figura 1. Entre as justificativas pode-se destacar o desinteresse decorrente do não estabelecimento de uma identificação ou relação direta entre homens e plantas (MENESES et al. 2009), fazendo com que muitos professores adotem um método pouco prático (SILVA, 2008), descontextualizado (BATISTA; ARAÚJO, 2015) e fragmentado (SANTOS et al. 2018) de ensino, subvalorizando o assunto (KINOSHITA et al. 2006) e, por vezes, assumindo uma postura de insegurança e desconforto em relação à temática (SANTOS; CECCANTINI, 2004). Isso decorre, 
possivelmente, também de uma formação científica baseada em modelos tradicionais (STOFFLETT, 1999) e especificamente insuficiente em botânica e portanto, este professor não têm como nutrir entusiasmo pelo assunto e obviamente não consegue motivar seus alunos no aprendizado da matéria (SALATINO; BUCKERIDGE, 2016). Além disso, some-se ainda o fato de que os livros didáticos trazem uma abordagem teórica e complexa dos conteúdos de Botânica, apresentados de forma cada vez mais distante da realidade de alunos e professores (STANSKI, et al. 2016).

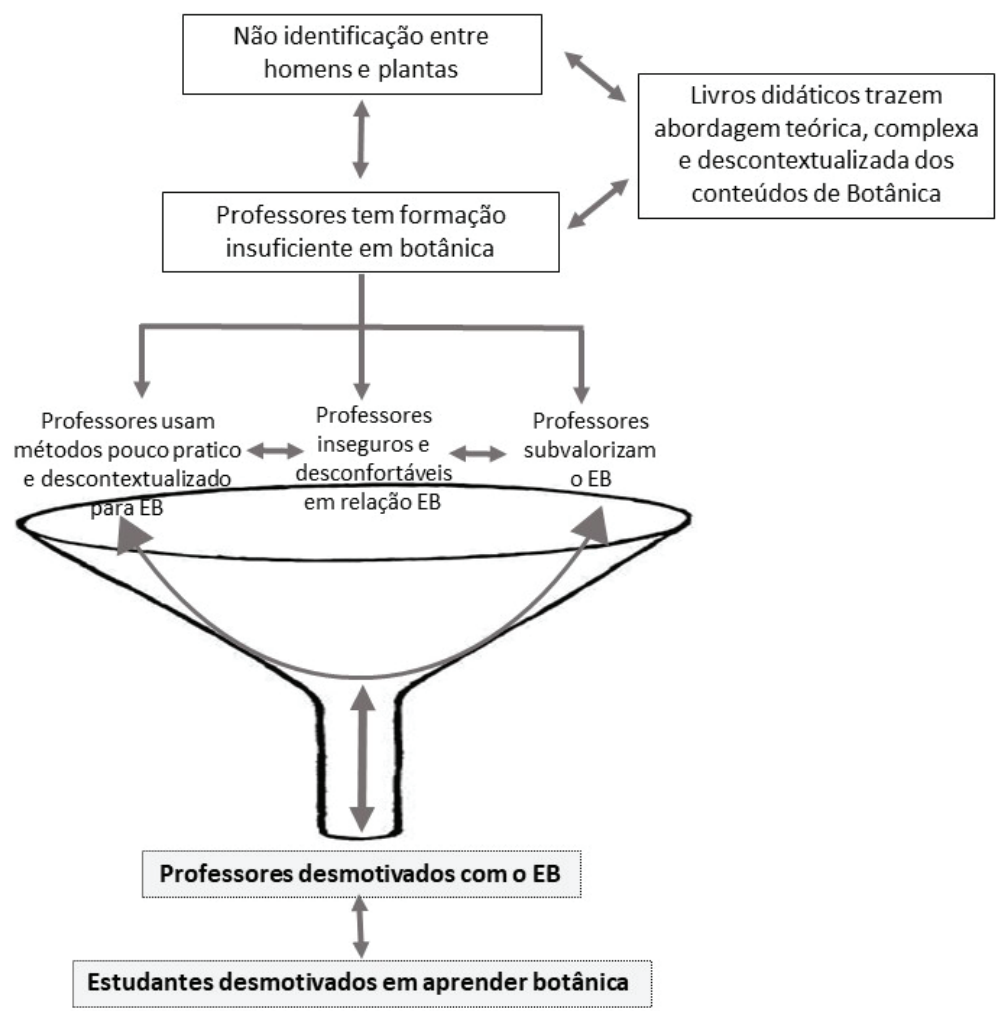

Figura 1 - Sistema cíclico que retroalimenta a desmotivação de professores e estudantes quanto os processos de ensino e aprendizagem dos conteúdos de Botânica. EB = ensino de Botânica.

A principal justificativa para as dificuldades de ensino aprendizagem dos assuntos da botânica, consenso entre diversos autores, está representada no topo da Figura 1. A não identificação entre Homem e Plantas vem sendo discutida na literatura como uma 'cegueira botânica', que segundo Katon et al. (2013) é pontuada como a dificuldade de reconhecer as plantas no cotidiano, para além de apenas como um cenário da vida dos animais; não reconhecer a importância dos vegetais na biosfera, nas atividades diárias e nos ciclos biogeoquímicos, provocando uma visão equivocada das plantas, considerando-as seres desinteressantes e inferiores aos animais. Este pensamento pode ser tido como o ponto de partida para a falta de motivação e envolvimento nos estudos dos vegetais, desfavorecendo a aquisição dos conhecimentos botânicos no ensino básico. 
Partindo desse aspecto central, eventos em cascata dão forma a esse mecanismo de retroalimentação negativa, em que o professor desmotivado adota estratégias de ensino meramente descritivas, fragmentadas e descontextualizadas, o que faz com que, segundo Santos et al. (2018), o aluno não consiga estabelecer relações entre a biologia vegetal, o meio ambiente e o contexto da sua vida real, o que inviabiliza uma visão geral e integradora do conhecimento.

Por isso, a quebra desse ciclo vicioso de desmotivação é tarefa urgente para botânicos e especialistas em ensino de Biologia, sob pena de drásticas consequências para a sociedade, uma vez que o estudo da botânica é essencial para a prática cidadã, na medida em que fornece conhecimento para que os sujeitos compreendam e possam enfrentar desafios atuais (SALATINO; BUCKERIDGE, 2016). Desafios estes tão dramáticos como a escassez de água, desmatamentos e perda da biodiversidade, produção de alimentos saudáveis, medicamentos, poluição atmosférica e hídrica, desenvolvimento de novas técnicas agrícolas, etc. Portanto, a aquisição dos conhecimentos sobre o mundo vegetal é de extrema importância na educação básica, e por isso o ensino de botânica tem sido alvo de grande preocupação entre os pesquisadores (HOEHNE, 1937; SENICIATO; CAVASSAN, 2004; TOWATA et al. 2010; SILVA, 2013; SALATINO; BUCKERIDGE, 2016; SANTOS et al. 2018).

Entre as propostas apresentadas, destaca-se a necessidade de novos caminhos metodológicos na prática docente (KINOSHITA et al. 2006) como gatilho propulsor da motivação de professores e estudantes. A motivação do aluno é uma variável extremamente relevante do processo ensino-aprendizagem, uma vez que que o rendimento escolar não pode ser explicado unicamente por conceitos como inteligência, contexto familiar e condição socioeconômica (LORENÇO e PAIVA, 2010). Pozo e Crespo (2009) relatam que para muitos professores a falta de motivação é o principal problema que enfrentam, e destacam que:

'Os alunos não estão interessados na ciência, não querem se esforçar e nem estudar e, por conseguinte, dado que aprender ciência é um trabalho intelectual complexo e exigente, fracassam. Não há dúvidas que este é um diagnóstico certeiro, uma vez que a motivação é um dos problemas mais graves do aprendizado em qualquer área não apenas em ciências.'(POZO e CRESPO, 2009, p. 40)

Ainda segundo os autores, a motivação é uma via de mão dupla, pois "os alunos não aprendem porque não estão motivados, mas, por sua vez, não estão motivados porque não aprendem" (POZO e CRESPO 2009, p. 40). Portanto, a motivação influencia de maneira determinante o comportamento e ações dos indivíduos, isto é, impulsionam determinadas ações específicas e determina sua persistência nelas ou não. Em outras palavras, a escolha 
de realização de certas atividades se dá pelo interesse, que tem como motivo a geração de alguma forma de satisfação. A verdadeira motivação pela ciência se dá na busca pelas respostas e conhecimentos que lhe tragam a satisfação pessoal de compreender o tema. Assim, impulsionar este desejo de aprender parece ser o caminho para a construção de um conhecimento mais estável e duradouro. Portanto, fazer com que o aluno participe ativamente do processo de construção do conhecimento científico amplia a busca por significados e interpretações. Neste sentido, destacamos o papel do docente na busca por práticas diferenciadas, que estabeleçam um mecanismo de motivação tanto para o professor quanto para os alunos, os quais, por sua vez, irão engajar-se na construção do conhecimento, ao invés de reduzir a aprendizagem a um processo repetitivo e enfadonho.

Apesar do ensino tradicional de botânica estar pautado na memória auditiva e visual, o uso de estratégias alternativas e práticas educativas diversificadas, que busquem explorar outros sentidos dos alunos, podem constituir poderosas ferramentas de mediação para a promoção da motivação. Lemke (1998) destaca que a Ciência não representa o mundo apenas por meio das palavras, mas sim de um modo mais amplo, por meio de uma integração sinérgica de palavras, diagramas, figuras, gráficos, mapas, equações, tabelas, gráficos e outras formas de expressão.

Essas estratégias de diversificação nos métodos de ensino têm sido amplamente valorizadas com a finalidade de melhoria da qualidade da aprendizagem. Tais estratégias que buscam variadas maneiras de se abordar um mesmo assunto, visam tornar os tópicos mais concretos e interessantes para o ensino, trazendo assim resultados positivos de aprendizado dos alunos (ZOMPERO; LABURÚ 2010; SANTOS et al. 2018).

Nessa proposta pedagógica, os modelos didáticos representam ferramentas eficazes na articulação método-conteúdo e constituem processos representacionais que se utilizam de imagens, esculturas ou maquetes para auxiliar os alunos a visualizarem e compreenderem um conteúdo que se apresenta de difícil compreensão, complexo ou abstrato.

Segundo Krapas et al. (1997, p. 186), "na literatura de educação em ciências, o termo modelo aparece com frequência, mas assume diversos sentidos". Entre eles, nos interessam os modelos pedagógicos como uma representação simplificada de uma ideia, objeto, evento, processo ou sistema que se constitua em objeto de estudo, visando favorecer o processo de aprendizagem significativa, por parte dos alunos (KRAPAS et al. 1997). Nerssesian (1995), acrescenta ainda que a "modelagem construtiva é um processo de raciocínio integrador que emprega modelagem visual, analógica e experiências de pensamento, criando e transformando representações informais dos problemas". Para Cavalcante; Silva (2008), os modelos didáticos estão relacionados à experimentação, e a conexão teoria e 
prática. Por tal caminho, os estudantes poderão desenvolver condições para a compreensão dos conceitos, para o desenvolvimento de habilidades, competências e atitudes, além de uma análise crítica sobre o mundo em que vivem.

Nesse sentido, diversas iniciativas vêm tendo destaque nas pesquisas em ensino de Botânica. Modelos de cloroplastos e mitocôndrias, de cortes de plantas (Gianotto et al. 2011), de plantas terrestres inteiras (CHAVES et al. 2012), maquetes de cortes histológicos de órgãos vegetais, modelos de flores para simulação do processo de reprodução (SILVA et al. 2013), modelos sequenciais de árvore, folha, mesofilo, célula vegetal e cloroplasto (ARAÚJO et al. 2013), modelos comparativos de células vegetal e animal (SILVA et al. 2016), modelos de tropismos e condução de seiva (MOUL; SILVA, 2017) são alguns exemplos promissores do uso dos modelos didáticos aplicados ao ensino de Botânica. O uso desses modelos também se apresenta como estratégia para o ensino de botânica para alunos deficientes visuais, pois podem ser manuseados, como os modelos em biscuit das partes de flores e folhas e dos ciclos reprodutivos de Gimnospermas e Angiospermas apresentados por Pinheiro et al. (2015), permitindo ao professor além de garantir uma atividade inclusiva, facilitar a aprendizagem de todos os alunos, que também se sentem motivados com a possibilidade de tocar os materiais.

Entretanto, cabe ressaltar que apesar de uma alternativa eficiente e promissora, o uso de modelos didáticos não conta com tantas pesquisas quanto, por exemplo, o uso de jogos e outras estratégias, como ferramentas didáticas em ensino de Botânica.

Assim, na busca por diferentes linguagens para ensinar botânica e promover engajamento dos estudantes, passamos à análise da construção de modelos didáticos para o ensino de Botânica, por meio de uma perspectiva investigativa e colaborativa.

\section{O PROJETO DE INICIAÇÃO CIENTÍfICA JÚNIOR (PICJr) - Um Projeto colaborativo Universidade-Escola}

O projeto foi realizado em uma escola pública de ensino médio do município de Vitória - Espírito Santo (Brasil), como parte do Programa de Iniciação Científica Júnior (ICJr), apoiado e financiado pela Fundação de Amparo à Pesquisa do Espírito Santo (FAPES), em parceria com o Conselho Nacional de Desenvolvimento Científico e Tecnológico (CNPq). Teve como objetivo despertar em alunos de escolas públicas vocações científicas e tecnológicas, além de incentivar talentos potenciais na busca de recursos humanos de interesse para o desenvolvimento científico e tecnológico do estado do Espírito Santo.

A abordagem da pesquisa em questão é qualitativa, pois visa a compreensão de contextos e grupos sociais e preocupa-se com aspectos da realidade que não podem ser 
quantificados (SILVEIRA; CÓRDOVA, 2009). A escolha pela pesquisa-ação como modalidade de estudo deve-se à características situacionais e busca identificar um problema específico em uma realidade específica, com vistas ao alcance de resultados práticos (GIL, 2010).

O investigador abandona o papel de observador em proveito de uma atitude participativa e de uma relação sujeito a sujeito com os outros parceiros. O pesquisador quando participa na ação traz consigo uma série de conhecimentos que serão o substrato para a realização da sua análise reflexiva sobre a realidade e os elementos que a integram. A reflexão sobre a prática implica em modificações no conhecimento do pesquisador. (FONSECA, 2002, p. 35).

Para obtenção dos dados e avaliação foram adotados instrumentos de coleta e registros, tais como entrevistas, questionários e observações. O delineamento teórico e metodológico da análise foi a abordagem do desenvolvimento e aprendizagem pela perspectiva da Teoria Histórico Cultural (THC) de Vygotsky (VYGOTSKY, 2003), por meio da atividade mediada (WERTSCH, 1988), que requer o uso de artefatos mediadores (nesse caso a construção e aplicação dos modelos didáticos) como elos intermediários no processo de aprendizagem.

A investigação envolveu inicialmente oito alunos bolsistas de ICJr, das primeiras e segundas séries do ensino médio (com idades entre quatorze a dezessete anos), dois monitores graduandos do curso de licenciatura em Ciências Biológicas da Universidade Federal do Espírito Santo - UFES, a professora de biologia efetiva da escola e a professora da universidade coordenadora do projeto. Posteriormente, as atividades de aplicação dos produtos desenvolvidos pelo projeto alcançaram outros 90 estudantes das terceiras séries na escola e seus respectivos professores. $\mathrm{O}$ alvo das pesquisas e produções dos alunos foram os conteúdos de botânica pertinentes às séries finais do Ensino Fundamental e todo o Ensino Médio.

As questões norteadoras para a atividade de pesquisa dos alunos estavam centradas na melhoria da qualidade do ensino-aprendizagem escolar como um desafio na superação de dificuldades que faziam parte da realidade em que estavam inseridos diretamente. Assim, foram levantadas questões investigativas tais como: Quais são os conteúdos que os alunos têm maior dificuldade de compreensão? O que faz deles mais difícil do que os outros? Como podemos ajudar a solucionar esse problema?

A proposta metodológica teve como uma das etapas iniciais o levantamento das principais dificuldades encontradas na aprendizagem dos conteúdos de biologia, bem como a busca por propostas de melhoria. Para isso foi realizado um processo de investigação no qual os alunos 
do PICJr, por intermédio de entrevista estruturada com os professores e demais alunos da escola, buscaram identificar, por parte de ambos, quais os conteúdos da biologia apresentavam maior dificuldade de aprendizagem e quais seriam, em suas perspectivas, as possíveis soluções. A partir dos resultados obtidos pelas entrevistas e em reuniões de discussão e análise realizadas pelos alunos, foram estabelecidos os conteúdos de botânica como prioritários para a pesquisa e o método lúdico (jogos ou modelos didático-interativos) como a alternativa metodológica mais adequada.

Em um segundo momento, deu-se início à etapa de conceitualização: os estudantes dedicaram-se, coletivamente, à busca das informações provenientes da ciência erudita acerca dos conteúdos de botânica. Os alunos, com orientação dos professores da escola e da universidade e com acompanhamento dos monitores, puderam familiarizar-se com os termos e conceitos botânicos através de livros didáticos e da internet em reuniões semanais de estudo. Nesse momento os alunos puderam levantar hipóteses e relacionar a proposta do modelo didático com a linguagem científica.

A etapa seguinte consistiu em um momento de metacognição, em que os alunos puderam refletir e tomar consciência sobre os conceitos novos que deveriam incorporar na elaboração dos projetos de modelos didáticos. Essa etapa envolveu uma análise rigorosa por parte dos estudantes para que planejassem de modo hábil e coerente como explicar conceitos botânicos representados na forma de modelos. Segundo Galagovsky; Aduriz Bravo (2001), esta etapa constitui a parte de maior dificuldade pois requer um alto nível de conceitualização e revisão dos mecanismos próprios de aquisição de conhecimento, sendo tanto maior a dificuldade quanto menor a maturidade dos alunos para atividades autônomas de construção do conhecimento. Por isso, Souza et al. (2018) destacam o importante papel da mediação na realização de atividades coletivas como esta, pois é sabido que o trabalho em grupo delegado aos alunos sem nenhum tipo de acompanhamento, pode não alcançar os bons resultados almejados.

Na sequência, procedeu-se à pesquisa de materiais para definição da alternativa de melhor custo-benefício, ou seja, de baixo custo, porém de fácil manipulação e alta durabilidade. Outros modelos pedagógicos desenvolvidos com a mesma finalidade empregaram materiais como isopor, plástico, massa de modelar, massa de biscuit, resina e e.v.a. entre outros (ARAÚJO et al. 2013; PINHEIRO et al. 2015; MOUL; SILVA, 2017).

A última etapa foi a experimentação em sala de aula. Para a viabilização desse último momento, foram realizadas reuniões de planejamento com os professores regentes das turmas e adequação dos temas ao conteúdo pertinente de cada série. Então, a aplicação dos modelos foi realizada em três turmas de 30 alunos cada, em atividades lideradas pelos alunos de ICJr com o acompanhamento dos 
professores de biologia regentes da classe. Após esta etapa, foi feita a avaliação da aplicação dos modelos em aulas de biologia, como um estudo de campo por meio da observação direta do envolvimento e interesse dos alunos das turmas onde as aulas com os modelos foram realizadas (GIL, 2002). Por fim, foram distribuídos dois questionários: um para o professor da disciplina e outro para os alunos, ainda a fim de avaliar o uso dos modelos didáticos como ferramentas eficazes para o ensino de Botânica. Responderam aos questionários no total 3 professores de biologia e 90 alunos regulares da terceira série do ensino médio que participaram da aplicação dos modelos em aula.

\section{OS MODELOS DIDÁTICOS}

O conteúdo de botânica é lecionado na terceira série do Ensino Médio nas escolas públicas estaduais do Espírito Santo. Os professores, ao abordarem as dificuldades em ensinar Botânica, concordam com Longo (2012) que os conteúdos parecem abstratos e, muitas vezes, de difícil compreensão, e destacam como pontos negativos, a carência de materiais apropriados para a visualização e manejo de exemplares, sobretudo microscópios óticos para desenvolver a aula. Assim, evidenciam a dificuldade de ilustrar de modo prático os conceitos trabalhados na teoria.

Considerando que a falta de material apropriado pode ser fator limitante para o estímulo do aluno e percebendo, nas entrevistas, a constante busca do professor por recursos pedagógicos alternativos que facilitem a mediação da aprendizagem em sala de aula, os alunos participantes do PICJr se propuseram a contribuir na busca por soluções.

Após a etapa de conceitualização e estudo dos conteúdos, foram produzidos três modelos como material didático de apoio para a disciplina de biologia, nos conteúdos de botânica (descritos a seguir).

\section{Modelo Pteridófitas}

Objetivo: Permitir aos alunos a visualização/manipulação do ciclo de vida das pteridófitas.

Descrição: Modelo tridimensional feito em massa de biscuit do ciclo de vida das pteridófitas. Uma folha de samambaia (as mais estudadas dentre as pteridófitas) foi reproduzida; em sentido horário figura um detalhe da face inferior da folha, mostrando os soros, nos quais os esporos produzidos geralmente são levados pelo vento e germinam ao encontrar um substrato em condições favoráveis (ambientes úmidos) formando assim o prótalo, que corresponde ao gametófito das pteridófitas, ou seja, é o local onde ocorre a produção dos gametas. Após a fecundação da oosfera pelo anterozóide (gametas feminino e masculino, respectivamente), o zigoto se desenvolve até formar o embrião, que dará origem a um novo esporófito, isto é, 
formará uma nova samambaia, dando início a um novo ciclo de vida. Os modelos construídos em massa de biscuit foram organizados em caixas de acrílico transparente, nas quais também foi anexada uma figura-legenda. O modelo está disponível para a utilização pelos professores em sala de aula, pois permite melhor visualização dos elementos (Figura 2).

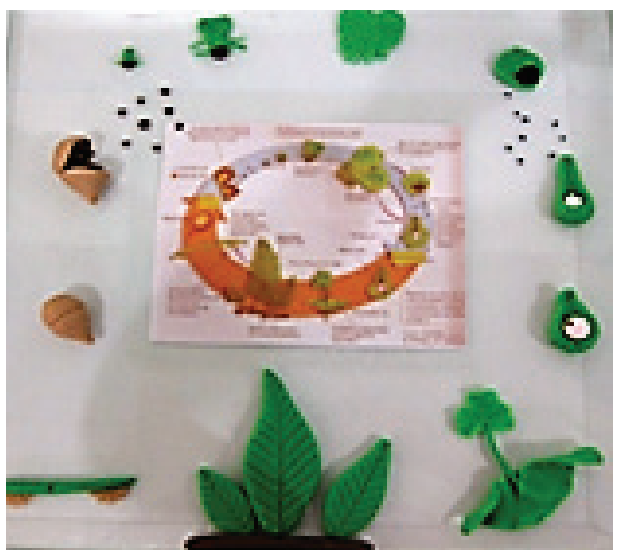

Figura 2 - Representação simplificada do ciclo de vida das pteridófitas desenvolvido por alunos do ensino médio em escola pública estadual do município de Vitória/ES.

\section{Modelo Angiospermas}

Objetivo: Permitir aos alunos a visualização/manipulação e compreensão das estruturas reprodutivas das angiospermas.

Descrição: Modelo tridimensional feito de massa de biscuit representando as estruturas reprodutivas das angiospermas. Este modelo evidencia a morfologia dos verticilos reprodutivos e protetores da flor. Os modelos foram organizados em caixa de acrílico transparente, na qual foi anexada uma figura-legenda. Assim como os demais modelos, este caracteriza-se por facilitar o entendimento do assunto, pois permite melhor visualização das estruturas e elementos (Figura 3).

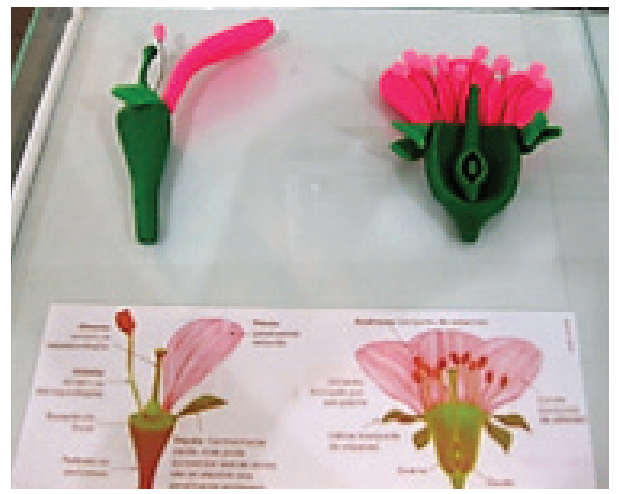

Figura 3 - Representação simplificada da biologia floral das angiospermas desenvolvida por alunos do ensino médio em escola pública estadual do município de Vitória ES. 


\section{Modelo Fecundação Floral}

Objetivo: Permitir aos alunos a visualização/manipulação e compreensão do processo de formação do gameta feminino vegetal.

Descrição: Modelo tridimensional feito em massa de biscuit representando o processo de formação do gameta feminino (megasporogênese ou megagametogênese). Da esquerda para a direita está representado o gineceu, um corte do ovário com o óvulo e o desenvolvimento do óvulo maduro no saco embrionário. No saco embrionário estão representados os núcleos que serão fecundados pelos dois núcleos espermáticos trazidos pelo pólen (a oosfera, originando um zigoto e os 2 núcleos polares, originando um tecido de reserva, o endosperma) no processo de dupla fecundação. A partir da fecundação floral (fusão dos núcleos dos gametas) tem-se a formação da semente e fruto nas angiospermas. Os modelos construídos em massa de biscuit foram organizados em caixa de acrílico transparente, onde também foi anexada uma figura-legenda (Figura 4).

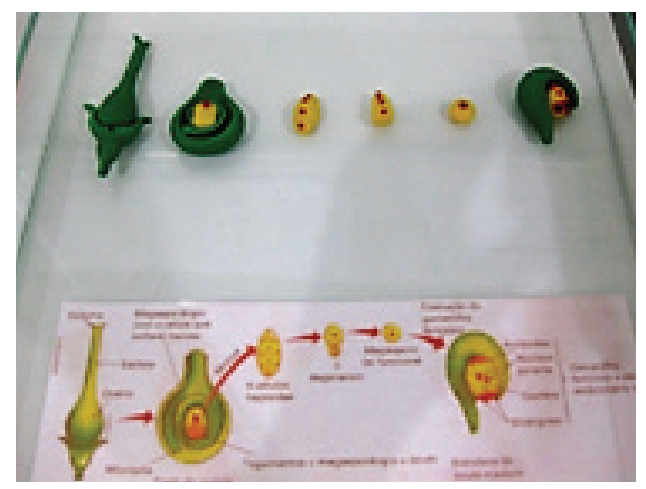

Figura 4 - Representação simplificada das etapas de formação do gameta feminino vegetal desenvolvido por alunos do ensino médio em escola pública estadual do município de Vitória ES.

Sabe-se que a utilização de atividades lúdicas no ensino pode ser uma ferramenta facilitadora no processo da aprendizagem, em especial quando se trata de assuntos abstratos e de difícil associação pelos alunos como, por exemplo, o ciclo de vida e reprodução dos vegetais. Nesse sentido, a construção dos modelos didáticos como uma linguagem diferente e lúdica, desenvolvidos em uma perspectiva investigativa e colaborativa, pode contribuir para a apropriação dos conteúdos de botânica pelos estudantes.

A apropriação de tais conhecimentos pode ser facilitada pelo uso de tipos diversificados de representação dos conceitos para que os estudantes desenvolvam ampla compreensão dos diversos modos de representar um determinado conteúdo (descritivas, figurativas, sinestésicas), sem que se tornem dependentes de um modo particular ligado a um ponto específico (PRAIN; WALDRIP, 2006). Assim, se os conceitos forem trabalhados através de pelo menos dois canais diferentes, a capacidade de aprendizagem dos alunos será potencializada (TAVARES, 2005). 
Considerando que os indivíduos possuem diferentes estilos de aprendizagem, ou seja, são capazes de assimilar de forma diferente as informações, Felder; Silverman (1988) formularam um modelo com 5 dimensões relevantes para melhorar a aprendizagem em relação à educação científica: visual/verbal, sensorial/intuitivo, indutivo/ dedutivo, ativo/reflexivo e sequencial/global. O conhecimento dessas dimensões se faz útil ao professor quanto ao planejamento de suas estratégias de ensino, para a escolha do melhor modo de se aplicar uma aula levando-se em consideração o entendimento do conteúdo pelos alunos.

Nesse caso, além do modelo visual/verbal comumente utilizado e disponível por meio do discurso e do livro, o uso dos modelos didáticos inclui as dimensões ativo/reflexivo (por meio da participação ativa dos estudantes nas tomadas de decisão quando da pesquisa, elaboração e construção dos modelos) e sensorial/intuitivo (pelo manuseio dos modelos tridimensionais) como estratégias associadas e complementares de ensino.

Ainda em uma perspectiva da valorização de estratégias e modelos diversificados de abordagem dos conteúdos, o método lúdico destaca-se "como promotor da aprendizagem nas práticas escolares, possibilitando a aproximação dos alunos ao conhecimento científico" (KNECHTEL; BRANCALHÃO, 2009). Na medida em que se apresentam como uma abordagem cativante, motivadora e divertida, as atividades lúdicas promovem a independência e o exercício da criatividade, tornando o processo de aprendizagem mais dinâmico e interessante, principalmente quando associadas ao cotidiano dos alunos. Neste sentido, atividades lúdicas são alternativas viáveis para uma aproximação prazerosa da relação professor - aluno - conhecimento científico.

Valente (1993) explica que o sucesso na construção e assimilação do conhecimento que ocorre ao utilizar atividades lúdicas no cotidiano da sala da aula, se dá pelo fato de o aluno aprender melhor quando é livre para descobrir relações por ele mesmo (exploração autodirigida), ao invés da instrução explícita e direta.

Portanto, a utilização de modelos tridimensionais, em especial quando é parte de um processo liderado e realizado pelos próprios alunos como protagonistas no processo, representa uma alternativa relevante e capaz de tornar as aulas de ciências e biologia mais atrativas. O uso de modelos tridimensionais vem suprir as limitações das figuras bidimensionais dos livros, de maneira que estimule a memória visual e sensorial dos alunos. Com o uso dos modelos em aula, pretende-se que o aluno seja capaz de associar tamanho, volume e localização de estruturas, de forma que permita uma aproximação da realidade, possibilitando uma aprendizagem significativa. A utilização desta estratégia de ensino contribui para o aprimoramento de modelos mentais, visto que, muitas vezes, o conceito prévio dos alunos não condiz com a realidade, especialmente nas questões relacionadas ao volume e proporções, 
favorecendo, desta forma, uma aproximação com o realismo científico.

No entanto, é muito importante que o aluno entenda que modelo é uma representação, um meio aproximado sobre o qual se pode raciocinar, estudar e manipular, mas que não é a realidade. A construção de modelos tridimensionais deve vir a incrementar a forma de construir a realidade, levando a melhoria na qualidade do conhecimento científico escolar.

\section{A APRENDIZAGEM PARTICIPATIVA COMO ESTRATÉGIA DE MOTIVAÇÃ̃O}

De acordo com os Parâmetros Curriculares Nacionais (2000) e Orientações Educacionais Complementares aos Parâmetros Curriculares Nacionais (2002) devem ser promovidas as estratégias de ensino que possibilitem aos discentes maior clareza dos objetivos de seus estudos, permitindo, ainda, que participem do processo de elaboração de recursos didáticos, definição dos temas e na elaboração de protocolos para o desenvolvimento das atividades. A pesquisa, planejamento e confecção dos modelos botânicos pelos próprios estudantes participantes do projeto de ICJr vai ao encontro destas recomendações dos PCN, proporcionando um ambiente motivador e favorecendo o processo de aprendizagem.

O PICJr deu aos alunos a oportunidade de serem protagonistas na construção do conhecimento. Dessa forma, ao sentirem-se responsáveis por sua própria aprendizagem, os alunos puderam encarar de forma diferente os conteúdos escolares - agora não mais como conhecimentos 'vazios' impostos verticalmente, mas como conhecimentos significativos, escolhidos e produzidos por eles de modo horizontal, coletivo e colaborativo. Como resultado, os alunos são motivados e sentem-se valorizados, como sujeitos participantes do processo de ensino-aprendizagem.

Concordamos com Cunha (2007) quando diz que "o estímulo aos processos criativos e a manutenção do prazer nas atividades (...) são princípios fundamentais no processo educacional". Aqui acrescentamos também, como indispensável no processo de educação, o sentimento de pertencimento, ou seja, o aluno precisa sentir-se parte daquele meio, daquele grupo e daquelas atividades. Ele precisa sentir-se parte importante, pois isso desperta seu envolvimento. Para isto , o aluno precisa ser atuante no processo e não apenas participar como mero coadjuvante ou, ainda pior, expectador. Nestes casos, infelizmente frequentes em nossas escolas, o resultado pode ser a alienação e o desinteresse, afinal, aquele não lhe parece o seu mundo.

Nessa mesma linha, Bordenave (1994) observa que as práticas adotadas pelo docente, que mobilizam os alunos para a participação efetiva no processo de ensino-aprendizagem, se mostram catalisadoras da construção do conhecimento duradouro. Ou seja, a participação do aluno em 
seu próprio processo de aprendizagem, tomando para si a responsabilidade, que seria apenas do professor, oportuniza ao aluno o desenvolvimento da 'auto expressão, [...] do pensamento reflexivo, do prazer de criar e recriar coisas, e, ainda a valorização de si mesmo pelos outros' (BORDENAVE, 1994, p. 16).

O aluno que exerce a prática participativa como construtor do conhecimento, e não apenas como mero receptor de saberes acumulados, se identifica com aquilo que aprende, pois interfere ativamente com suas ações no processo. Neste sentido, a adoção de propostas inovadoras de ensino, que contemplem a participação dos estudantes no planejamento e desenvolvimento de atividades em sala de aula constitui promissora estratégia para motivação dos estudantes, fazendo com que as aulas sejam mais agradáveis para alunos e professores (SANTOS, 2002).

\section{A APRENDIZAGEM COLETIVA E COLABORATIVA}

A interação social entre os estudantes envolvidos na tarefa, influencia não só a aprendizagem, mas também as relações de afetividade e o desenvolvimento de novas habilidades. Pela interação entre os indivíduos é possível promover um ambiente de aprendizagem coletiva e colaborativa. Neste ambiente é possível trabalhar o pensamento crítico individual e coletivo, o poder argumentativo, a capacidade de trabalhar em equipe e a de solucionar problemas em prol de um objetivo em comum (SOUZA, et al. 2018).

A Aprendizagem Colaborativa parte da idéia de que o conhecimento é resultado de um consenso entre os membros de uma comunidade originado a partir do que as pessoas construíram juntas, seja conversando, trabalhando na solução de problemas, estudos de casos, projetos, de forma direta ou indiretamente (TORRES et al. 2004). Assim, a pedagogia da Aprendizagem Colaborativa está centrada no grupo e não nos indivíduos, isoladamente. O indivíduo aprende do grupo e contribui individualmente para a aprendizagem dos outros. Há então uma interdependência entre a aprendizagem colaborativa e a aprendizagem individual (MEIRINHOS, 2007 in MINHOTTO; MEIRINHOS, 2011).

Vygotsky reforça o papel das atividades pedagógicas realizadas em grupo na perspectiva de que o conhecimento é construído socialmente, na interação entre pessoas (VYGOTSKY, 2003). É no trabalho em equipe que os estudantes adquirem a confiança e consideração dos seus colegas e professores e assim as relações interpessoais se tornam uma motivação para execução de um determinado trabalho (SOUZA, et al. 2018).

Nesse contexto de envolvimento coletivo e colaborativo, em prol da solução de questões investigativas (elaboradas pelos próprios estudantes), foi possível observar grande progresso na compreensão dos conceitos de 
botânica e interesse pelo conteúdo por parte dos alunos de ICJr participantes do projeto. Esse assunto era novo para todos os alunos envolvidos no projeto, pois faz parte do currículo das terceiras séries do ensino médio, e por isso, estes alunos (das primeiras e segundas) ainda não haviam estudado. Mesmo assim, aceitaram o desafio de aprender antecipadamente o conteúdo, devido ao fato de ter sido apontado como um dos assuntos mais difíceis de aprendizagem em biologia nas entrevistas prévias realizadas com os professores e alunos. A realização da tarefa exigiu grande esforço de todos os envolvidos em cooperação, entretanto, o fato de estarem trabalhando em grupo fez com que se sentissem mais confortáveis e capazes. Segundo Frantz (2001):

A educação e a cooperação são duas práticas sociais que, sob certos aspectos, uma contém a outra. Na educação pode-se identificar práticas cooperativas e na cooperação pode-se identificar práticas educativas. Entrelaçam-se e potencializam-se como processos sociais. A organização da cooperação exige de seus atores a comunicação de interesses, de objetivos, a respeito do qual precisam falar, argumentar e decidir (FRANTZ, 2001, p. 242).

O desenvolvimento do PICJr demonstrou o quão aplicável são as conclusões de Frantz (2001) e demais autores que valorizam as práticas sociais colaborativas no contexto educacional. Após definição dos assuntos botânicos a serem abordados e antes da confecção dos modelos, foi necessária uma etapa de estudo e pesquisas. Os conceitos precisam ser primeiramente compreendidos e fazer sentido, para que assim o aluno sinta-se confortável, ou seja, seguro e confiante, para tratar daquele tema. Segundo Souza et al. (2018), a atividade requer que o estudante desenvolva modelos mentais de representações de conceitos adquiridos para sua posterior criação. Isso envolverá atenção, presença e sintonia de grupo, que implica também pensar, registrar, analisar, refletir e avaliar em grupo ou individualmente, com ou sem ajuda do professor.

Os estudos dos conceitos botânicos foram realizados individualmente e em grupo por meio da leitura do livro didático e outros textos trazidos pelos monitores. Os alunos estudaram simultaneamente o mesmo assunto, mas cada um com uma fonte didática diferente. Durante as discussões, com suas palavras, cada estudante explicou aos outros o que havia entendido. Após as falas dos alunos, os monitores também fizeram suas explicações. Ao apresentar seus modos de entender aquele mesmo assunto, os monitores destacaram em suas falas as informações que haviam notado algum equívoco ou confusão nas falas dos alunos, sem é claro, apontar erros. Ao ouvir atentamente as versões dos monitores, os estudantes, por si próprios, foram capazes de detectar erros em suas falas e entendimentos. Nesse processo, os estudantes ensinaram o que aprenderam 
e ouviram de seus colegas muitas outras versões do mesmo assunto.

Tal como descrito por Teixeira (1999) e Souza (2018), os momentos de discussão possibilitam aos alunos externarem suas experiências e ideias, aplicarem os conhecimentos adquiridos e testarem os modelos explicativos. Como todos haviam estudando o assunto antes da reunião, puderam discutir e solucionar dúvidas entre si. Ao final das discussões, a partir das falas mais coerentes e simples, eles chegaram a um consenso teórico, construindo um mosaico de explicações coerentes e significativas. Foi na discussão entre pares, que os estudantes puderam exercitar o raciocínio e a capacidade de defesa de seus pontos de vista, bem como o respeito pelas ideias dos outros, favorecendo o desenvolvimento da sociabilidade, cooperação e respeito mútuo entre os alunos. Tais observações concordam com Souza et al. (2018) quando destacam que (...) para que haja desenvolvimento e aprendizagem durante uma atividade colaborativa é necessário que o grupo construa coletivamente suas opiniões a respeito dos assuntos em questão por meio do debate e argumentação entre os integrantes do grupo (SOUZA et al. 2018, p. 138).

Então, além da perspectiva positiva relatada quanto à compreensão dos conceitos botânicos e à conquista do envolvimento e motivação dos alunos, é importante destacar que as atividades realizadas coletivamente, agregaram outros benefícios educacionais de grande valor, tais como: a socialização dos conhecimentos entre os alunos, o exercício da democracia, a compreensão e o respeito às diferentes formas de aprender e trabalhar, e a auto-organização. Essas habilidades foram exercitadas pelos estudantes, pois todas as tomadas de decisão (escolha do tema a partir da interpretação das entrevistas, estudo em grupo, escolha dos projetos, escolha dos materiais, a construção e aplicação dos modelos) foram amplamente debatidas e o consenso foi estabelecido de forma democrática, como se pode evidenciar por trechos das falas dos alunos abaixo:

- 'Podemos usar isopor, massinha, resina, biscuit, papel... ou o que mais?'

- 'Madeira também... se tiver alguém que nos ajude a trabalhar.'

- 'Madeira é durável, mas é difícil, isopor é mais fácil, mas quebra fácil também.'

- 'Isopor é feio. Não dá bom acabamento.'

- 'Acho que modelos de resina ficaria bem bonito, podemos ver um tutorial na net!'

- 'Deve ser caro.'

- 'Vamos pesquisar preços.'

- 'Podemos ver também materiais reciclados de casa mesmo.'

- 'Boa idéia!'

- 'Bom, vamos pesquisar em casa coisas tipo preço, durabilidade e como usa e para o próximo encontro cada um traz sua ideia de proposta dos materiais, ok!' 
Nessa dinâmica de argumentações e defesas de pontos de vista, nota-se grande crescimento na capacidade de expressão oral e também nos aspectos relativos à autoconfiança e responsabilidade com o trabalho. Em diversos momentos foram apresentados questionamentos e negociadas propostas de soluções. Também foram necessárias intervenções para a mediação de conflitos e divergência de interesses e opiniões. E é nesse contexto que se dá a aprendizagem significativa (TEIXEIRA, 1999). O mesmo autor ainda destaca que a relação com o outro 'permite um avanço maior na organização do pensamento do que se cada indivíduo estivesse só' (TEIXEIRA, 1999, p.26).

O trabalho em grupo é uma oportunidade de troca, momento em que o os alunos se deparam com diferentes percepções e são impulsionados a construir coletivamente o conhecimento. Neste tipo de tarefa, o aluno é convidado a ouvir e respeitar opiniões diferentes e chegar a um consenso de forma democrática.

Por fim, mas não menos importante, pode ser ressaltada como prática educacional de grande valor a socialização do conhecimento entre os alunos, uma vez que os alunos ICJr levaram os modelos para aplicação na prática da sala de aula. Este momento marca a valorização dos conhecimentos e do trabalho dos alunos ICJr (orgulhosos de seus produtos ali apresentados), mas também a conquista da adesão dos demais colegas, que por verem seus 'iguais' dominando aqueles conteúdos, puderam experimentar a sensação de que o aprendizado era possível, afinal, se seus colegas aprenderam, eles também poderiam facilmente aprender. A participação dos alunos ICJr junto ao professor regente das turmas ajudou na quebra do paradigma do 'conteúdo difícil'. Nesse caso, com uma dupla ajuda: a dos modelos didáticos e a abordagem dos colegas falando a 'mesma língua e tornando o ambiente mais descontraído'.

Essa foi a percepção dos três professores regentes das turmas nas quais os modelos foram aplicados, pois todos avaliaram o desenvolvimento da atividade em parceria com os alunos ICJr como excelente e afirmaram que repetiriam a atividade com suas próximas turmas, pois consideraram que o método contribuiu facilitando a compreensão do conteúdo pela turma. Os professores inclusive destacaram, com entusiasmo, a grande participação e envolvimento da turma durante a aula, o que, segundo um dos professores 'não era normal de acontecer nas suas aulas de botânica'.

Os alunos das turmas cuja atividade foi realizada com o uso dos modelos didáticos relatam terem gostado da atividade (96\% das respostas), que foi mais fácil manter a atenção durante a aula ( $98 \%$ das respostas) e que gostariam de ter mais aulas assim (97\% das respostas). Em alguns comentários abertos, os alunos destacaram:

- 'Foi muito legal ouvir a explicação deles [colegas]!'

- 'Eles [colegas] falam mais fácil e engraçado!'

- 'Foi uma dinâmica divertida. Nunca imaginei ter uma aula com um colega do $2^{\circ}$ ano!' 
- 'Acho legal poder tocar os modelos.. acho que enxergo também com as mãos (risos).'

- 'A aula foi diferente e eu gosto disso.'

\section{CONSIDERAÇÕES FINAIS}

O desafio representado pelos conteúdo da botânica para muitos professores e estudantes no ensino médio pode ser vencido por meio de metodologias alternativas que favoreçam a integração entre o conteúdo e as atividades práticas, estimulando assim o engajamento e participação ativa dos estudantes no processo de aprendizagem. Nesse contexto, é possível destacar como promissor o uso dos modelos didáticos como facilitadores no processo de ensino-aprendizagem de conceitos de botânica, em aulas teóricas por meio dos quais os alunos possam visualizar e manipular os materiais tornando a teoria mais palpável e real para o estudante.

O diferencial da proposta consiste na autonomia do estudante, que em todas as etapas (pesquisa, estudo, elaboração do projeto e construção dos modelos) teve a responsabilidade de decisão acerca dos conteúdos prioritários, os quais foram escolhidos e trabalhados de modo coletivo e colaborativo, com o objetivo altruísta de contribuir para a facilitação da aprendizagem dos colegas.

O PICjr demonstrou que práticas investigativas aliadas à construção dos modelos em um trabalho participativo, coletivo e colaborativo possibilita ao aluno o desenvolvimento da capacidade de construir o seu próprio conhecimento, demonstrado pelo grande domínio dos conceitos adquiridos pelos alunos e também o desenvolvimento de habilidades como liderança, auto-confiança, socialização, capacidade crítica, de argumentação e respeito.

Além disso, mostrou-se uma importante estratégia integradora, capaz de despertar nos colegas em sala de aula o interesse e o engajamento pelo assunto, tornando a aula mais interessante, as relações mais horizontais e, assim, facilitando a assimilação de conceitos relacionados à botânica.

\section{REFERÊNCIAS}

ARAÚJO, Vanessa Kelly Rodrigues de; CUNHA, José Alberes Santos da; SANTOS, Danielle Melo dos; SOUZA, Jonathas Lins.; SILVA, Eduardo Pereira Duarte da; VASCONCELOS, Argus de Almeida. Aplicabilidade alternativa para o ensino do processo fotossintético em sala de aula. In: XIII Jornada de Ensino, Pesquisa e Extensão, 2013. Recife, PE: Anais eletrônicos. Universidade Federal Rural de Pernambuco - UFRPE, 2013. Disponível em: http://www.eventosufrpe.com.br/2013/cd/trabalhos. htm. Acesso em 22 ago. 2017. 
BATISTA, Leandro; ARAÚJO, Joelisa. A Botânica sob o olhar dos alunos do ensino médio. Revista Areté| Revista Amazônica de Ensino de Ciências, Manaus, Universidade do Estado do Amazonas, v. 8, n. 15, p.109120, 2015 .

BORDENAVE, Juan Diaz. O que é participação. 8ed. São Paulo: Brasiliense. 1994.

BRANCO, A. L. C.; VIANA, I. B.; RIGOLON, R. G. A utilização do jogo "Perfil Botânico" como estratégia para o ensino de botânica. In: VIII Encontro Nacional de Pesquisa em Educação em Ciências,2011, Minas Gerais. Resumos... Disponível em: <http://www.nutes.ufrj.br/ abrapec/viiienpec/resumos/R1295-1.pdf > Acesso em: 15 mar. 2015.

BRASIL. Parâmetros Curriculares de Ensino Médio + Orientações Educacionais Complementares aos Parâmetros Curriculares Nacionais - PCEM, 2002.

CAVAlCANTE, Dannuza Dias; SILVA, Aparecida de Fátima Andrade da. Modelos didáticos e professores: concepções de ensino-aprendizagem e experimentações. In: XIV Encontro Nacional de Ensino de Química, 2008. Curitiba, PR. Anais... Curitiba, PR: Universidade Federal do Paraná, 2008. Disponível em: http://www.quimica. ufpr.br/eduquim/eneq2008/resumos/Ro519-1.pdf Acessado em 11 de Out. de 2017.

CHAVES, Rafaela Santos.; MORAES, Simone Souza de; LIRA-DA-SILVA, Rejane Maria. Aplicação de modelos didáticos tridimensionais de plantas extintas no ensino da conquista do ambiente terrestre pelas plantas. In: I Congreso Latinoamericano de Investigación en Didáctica de las Ciencias Experimentales, 2012, Santiago do Chile. Atas... Santiago do Chile, Chile. Pontíficia Universidade Católica del Chile. 2012.

CUNHA, Nylse Helena Silva. Criar para Brincar. São Paulo: Aquariana. 2007.

FELDER, Richard M.; SILVERMAN, Linda Kreger. Learning and teaching styles in engineering education. Journal of Engineering Education, Washington, USA, v.78, n.7, p. 674-681. 1988.

FONSECA, João José Saraiva da. Metodologia da pesquisa científica. Fortaleza: UEC, 2002. Apostila.

FRANTZ, João Carlos. O sentido político pedagógico da metodologia do prorenda. 2001. 168p. Dissertação (Mestrado em Educação) programa de Pós-Graduação em Educação nas Ciências. Faculdade de Educação. Universidade Regional do Noroeste do Estado do Rio Grande do Sul-UNIJUI, Santa Rosa., 2001. 
GALAGOVSKY,Lydia.;ADÚRIZ-BRAVO,Agustin. Modelos y Analogias en la Enseñanza de las Ciencias Naturales: el concepto de modelo didáctico analógico. Enseñanza de Las Ciencias. Madri, ES, Editora Educación. v. 19, n.2, p.231-242. 2001.

GIANOTTO, Dulcinéia Ester Pagani.; MACHADO, Marion Haruko; SERT, Maria Aparecida.; LIMA, Flávia Sicielli de. Elaboração e utilização de materiais pedagógicos de botânica e zoologia por professores de biologia. In: V Encontro Regional Sul de Ensino de Biologia (EREBIOSUL) e IV Simpósio Latino Americano e Caribenho de Educação em Ciências do International Council of Associations for Science Education (ICASE). Londrina: UEL. 18 a 21 de Set. de 2011. CD Room

GIL, Antonio Carlos. Como classificar as pesquisas? 4.ed. São Paulo: Atlas, 2002.

GIL, Antonio Carlos. Como elaborar projetos e pesquisa. $5^{\mathrm{a}}$ ed. São Paulo: Atlas, 2010.

HOEHNE, Frederico Carlos. Programa instructivo e educativo.In:ResenhaHistóricaparaaComemoração do Vigésimo Aniversário da Seção de Botânica e Agronomia Anexa ao Instituto Biológico de São Paulo. São Paulo: Secretaria de Agricultura, Indústria e Comércio, 1937.

HOBSBAUM, Angela; PETERS, Sandra; SYLVIA, KAthy. Scaffolding in Reading Recovery. Oxford Review of Education, Oxford, UK, University of Oxford, v.22, n.1, 17-34, 1996.

KAPRAS, Sayonara Salvador Cabral; Queiroz, Glória; Colinvaux, Dominique; Franco, Creso. Modelos: uma análise de sentidos na literatura de pesquisa em ensino de ciências. Revista Investigação no Ensino de Ciências, Porto Alegre: Instituto de Física - UFRGS, v.2, n.3, p.185202, 1997.

KATON, Geisly França.; TOWATA, Naomi.; SAITO, Luis Carlos. A cegueira botânica e o uso de estratégias para o ensino de botânica. In: III Botânica no Inverno. LOPEZ, Alejandra Matiz; NAGAI, Alice; FARIA, André Vinicius Fonseca ; PALACIOS, Carmen; IHA, Cíntia; PIKART, Filipe Christian; KATON, Geisly; BRASILEIRO, Juliana Castelo Branco; GAGLIARDI, Karina Bertechine; SANTOS, Kátia Pereira; RODRIGUES, Keyla; HAMACHI, Leonardo; DEVECCHI, Marcelo Fernando; OLIVEIRA NETO, Mário Albino; OLIVEIRA, Paulo Marcelo Rayner MIOTO, Paulo Tamaso (Orgs.). Instituto de Biociências da Universidade de São Paulo, São Paulo. 2013. Apostila.

KINOSHITA, Luiza Sumiko; TORRES, Roseli Buzanelli.; TAMASHIRO, Jorge Yoshio ; FORNI-MARTINS, Eliana 
Regina. (Orgs). A Botânica no Ensino Básico: relatos de uma experiência transformadora. São Carlos: Rima. 2006.

KNECHTEL, Carla Milene BRANCALHÃO, Rose Meire Costa. Estratégias Lúdicas no Ensino de Ciências. 2009. Disponível em: http://www.diaadiaeducacao. pr.gov.br/portals/pde/arquivos/2354-8.pdf. Acesso em: 20 de Out. de 2014.

KRAPAS, Sonia; QUEIROZ, Glória; Colinvaux, Dominique; FRANCO, Creso. Modelos: uma análise de sentidos na literatura de pesquisa em Ensino de Ciências. Investigações em Ensino de Ciências, Porto Alegre, RS, Instituto de Física - UFRGS, v. 2, n. 3, p.185-205. Dez.1997.

LEMKE, Jay L. Teaching all the languages of science: words, symbols, images and actions. Brooklyn College, City University of New York. 1998. Disponível em http:// academic. brooklyn. cuny. ed/education/jlemke/ (acesso em 06-XI-2014).

LONGO, Vera Carolina Cambréa. Vamos jogar? - jogos como recursos didáticos no ensino de ciências e biologia. Prêmio Professor Rubens Murillo Marques 2012: incentivo a quem ensina a ensinar/Fundação Carlos Chagas. São Paulo: FCC/SEP. p. 129 - 157. 2012.

LOURENÇO, Abílio Afonso.; PAIVA, Maria Olimpia Almeida. A motivação escolar e o processo de aprendizagem. Ciências e Cognição, Rio de Janeiro, Universidade Federal do Rio de Janeiro, v. 15, n. 2, ago. 2010.

MENEZES, Luan Cardoso; SOUZA, Vênia Camelo.; NICOMEDES, Mário Pereira.; SILVA, Natali Azevedo.; QUIRINO, Max Rocha.; OLIVEIRA, Ademir. Guilherme.; ANDRADE, Rodrigo Roneli; SANTOS, Betânia Araújo Cosme. Iniciativas para o aprendizado de botânica no ensino médio. In: XI Encontro de Iniciação à Docência. 2009. João Pessoa, PB, Anais... João Pessoa, PB: UFPB, 2009.

MINHOTO, Paula; MEIRINHOS, Manuel. As redes sociais na promoção da aprendizagem colaborativa: um estudo no ensino secundário. Educação, Formação \& Tecnologias, Educom - Associação Portuguesa de Telemática Educativa, 4(2), 25-34. 2011.

MOUL, Renato Araújo Torres de Melo; SILVA, Flávia Carolina Lins da. A construção de conceitos em botânica a partir de uma sequência didática interativa: proposições para o ensino de Ciências. Revista Exitus, Santarém, PA, Instituto de Ciências da Educação/ICED - UFOPA, v. 7, n. 2, p. 262-282, 2017. 
NERSESSIAN, Nancy J. Should Physicists Preach What They Practice? Constructive Modeling in Doing and Learning Physics. Science \& Education, Springer Netherlands, v.4, n.3, 203-226. 1995.

NEVES, Mônica Araújo; Araujo, Karla Caroline Muniz; Serejo, Maria Teresa Tavares; ROJAS, Mariano Oscar Ibañez; OLIVEIRA, Marcelo Moizinho Oliveira. Influência dos jogos como atividades lúdicas no curso de formação de professores em Química do IFMA. In: XV Encontro Nacional de Ensino de Química, 2010. Brasília, DF. Anais. Brasília. DF, UnB, 2010. Disponível em: http://www.sbq. org.br/eneq/xv/resumos/Ro558-1.pdf. Acesso em: 13 de Outubro de 2014.

PINHEIRO, Fernanda de Lima; SOARES, Brasília Castelhano; FIGUEIREDO, Suélem Martins; REPETTO, Vera Beatriz Borgmann; SILVA, Fabiane Ferreira da; MARINHO, Julio Cesar Bressolin. A otimização do ensino e aprendizagem de alunos cegos através de um projeto de botânica. In: VII Salão Internacional de Ensino, Pesquisa e Extensão, 2015. Anais ..., v.7, n.3, 2015. Universidade Federal do Pampa, 2015. Disponível em: <http://seer.unipampa.edu.br/index.php/siepe/article/ view/15056/4682>. Acesso em 19 de Jan. De 2017.

POZO, Juan Inacio; CRESPO, Miguel. Ángel G. A aprendizagem e o ensino de ciências. Porto Alegre: Artmed, 2009.

PRAIN, Vaughan; WALDRIP, Bruce.An exploratory study of teachers' and students' use of multi-modal representations of concepts in primary science. International Journal of Science Education, v28, n.15, p.1843-1866. 2006.

RESCHKE, Maria Janine Dalpiaz; PAULETTO, Elza Maria Kratz. Brinquedoteca: Espaço lúdico-científico desafios e possibilidades na formação de professores. In: III Simpósio Internacional e VI Fórum nacional de Educação, 2009. Torres, RS. Anais....Torres, RS: UERGS, 2009.

SALATINO, Antonio; BUCKERIDGE, Marcos. "Mas de que te serve saber botânica? Estudos avançados, São Paulo, SP, Instituto de Estudos Avançados, Universidade de São Paulo, vol.3o no.87 Mai./Ago. 2016.

SANTOS, Camila Reis dos; CORTE, Viviana Borges; LEITE, Idalina Tereza de Almeida. Técnicas de histologia vegetal no ensino médio: perspectivas de aproximação entre a escola e a universidade. In: ARAÚJO, Michell Pedruzzi Mendes; CORTE, Viviana Boges (ORG). O Ensino de Ciências e Biologia em uma perspectiva crítica. São Carlos: Pedro \& João Editores, 2018. 291p.

SANTOS, Deborah Yara Alves Cursino dos; CECCANTINI, Gregório. Propostas para o ensino de Botânica. 
Manual do curso para atualização de professores dos ensinos fundamental e médio. São Paulo: Apostila do Departamento de Botânica, Universidade de São Paulo, 48p. Disponível em: http://felix.ib.usp.br/Apostila_PEB. pdf. 2004. Acesso em 10 de Set. de 2014.

SANTOS, Josivaldo Constantino. A participação ativa e efetiva do aluno no processo ensino-aprendizagem como condição fundamental para construção do conhecimento.2002. Dissertação(MestradoemEducação) Programa de Pós-Graduação em Educação da Faculdade de Educação da Universidade Federal do Rio Grande do Sul, Porto Alegre, 2002. Disponível em: http://www. lume.ufrgs.br/bitstream/handle/10183/2313/o00317617. pdf?sequence $=1 \&$ locale $=$ pt_BR. Acesso em: 8 de Dez. de 2014.

SENECIATO, Tatiana; CAVASSAN, Osmar. Aulas de campo em ambientes naturais e aprendizagem em ciências: um estudo com alunos do ensino fundamental. Ciência e Educação, Bauru, SP, UNESP, v.10, n.1, p.133-47. 2004.

SILVA, Amanda. Reis da; CARMO, Silvio H. L.; MENEZES, Moirah. Paula Machado. Materiais didáticos alternativos para o ensino de botânica. In: $64^{\circ}$ Congresso Nacional de Botânica. Belo Horizonte, 2013. Anais eletrônicos. Belo Horizonte, SBB, 2013. Disponível em:http://www. botanica.org.br/trabalhos-cientificos/64CNBot/resumoins18861-id4973.pdf. Acesso em 28 de Ago. De 2014.

SILVA, Artemisia Amorim da; SILVA FILHA, Raimunda Trajano da; FREITAS, Silvia Regina Sampaio. Utilização de modelo didático como metodologia complementar ao ensino da anatomia celular. Biota Amazônica, Macapá, AP, Universidade Federal do Amapá, v.6, n.3, p. 17-21, 2016.

SILVA, João Rodrigo Santos. Concepções dos professores de Botânica sobre ensino e formação dos professores. São Paulo, 2013. 208p. Tese (Doutorado em Botânica) - Instituto de Biociências da Universidade de São Paulo, Departamento de Botânica, USP. São Paulo, 2013.

SILVA, Patricia Gomes Pinheiro. O ensino da botânica no nível fundamental: um enfoque nos procedimentos. 2008. Tese (Doutorado em

Educação para a Ciência) Programa de Pós-Graduação em Educação para a Ciência , Universidade Estadual Paulista, Bauru, SP, 2008..

SILVEIRA, Denise Tolfo; CÓRDOVA, Fernanda Peixoto. A pesquisa científica. In: SILVEIRA, Denise Tolfo; GERHARDT, Tatiana Engel (eds.). Métodos de pesquisa. Porto Alegre, RS: Editora da UFRGS, 2009. Disponível em: <http://www.ufrgs.br/cursopgdr/downloadsSerie/ derado05.pdf. 
Souza, Niliene Aparecida de; Corte, Viviana Borges; Batitucci, Maria do Carmo Pimentel; Volponi, Fabiano Caprini. Aprendizagem coletiva: uma proposta de mediação dos trabalhos escolares. In: ARAÚJO, Michell Pedruzzi Mendes; CORTE, Viviana Boges (orgs.). O Ensino de Ciências e Biologia em uma perspectiva crítica. São Carlos: Pedro \& João Editores, 2018. 291p.

STANSKI, Carin; LUZ, Cynthia Fernandes Pinto; RODRIGUES, Adriana Ribeiro Ferreira; NOGUEIRA, Melissa Koch Fernandes de Souza. Ensino de Botânica no ensino fundamental: estudando o pólen por meio de multimodos. Hoehnea, São Paulo, Instituto de Botânica de São Paulo, 43 (1), 2016.

STOFFLET, Rene T. Putting Constructivist Teaching into Practice in Undergraduate Introductory Science. Eletronic Journal of Science Education, Fort Worth, TX, Texas Christian University, v.3, n. 2, 1999.

Tavares, Romero. Animações interativas e mapas conceituais. In: XVI Simpósio Nacional de Ensino de Física, 2005. Rio de janeiro, RJ. Anais... CEFET-RJ, 2005.

TEIXEIRA,CíceraF.Compreensão,criaçãoeresolução de problemas de estrutura multiplicativa: uma sequencia didática com problemas abertos. 1999. Monografia (Especialização). Curso de especialização em ensino de pré a $4^{\text {a }}$ série. Universidade Federal de Pernambuco, Recife, PE, 1999.

TORRES, Patrícia Lupion; ALCANTARA, Paulo R.; IRALA, Esrom Adriano Freitas. Grupos de Consenso: uma proposta de aprendizagem colaborativa para o Processo Ensino Aprendizagem. Revista Diálogo Educacional, Curitiba,PR, Pontifícia Universidade Católica do Paraná, v.4, n.13, p.129-145, 2004.

TOWATA, Naomi; URSi, Suzana; SANTOS, Débora Yara Alves Cursino dos. Análise da percepção dos licenciandos sobre o "ensino de botânica da educação básica". Revista da SBenBio, São paulo, SP, Universidade de São Paulo, v.3, p.1603-12, 2010.

Valente, José Armando. Computadores e conhecimento: Repensando a educação. Segunda edição (1998). Campinas, SP: Nied, Unicamp. 1993.

VYGOTSKY, Lev Semionovich. A formação social da mente: o desenvolvimento dos processos psicológicos superiores. Ed. Martins Fontes, 2003.

WERTSCH, James V. Vygotsky y la formación social de la mente. Ed. Paidos Iberica,1988. 
ZÔMPERO, Andréia de Freitas; LABURÚ, Carlos Eduardo. 2010. As relações entre aprendizagem significativa e representações multimodais. Revista Ensaio Pesquisa em Educaçãoem Ciências, Belo Horizonte, Universidade Federal de Minas Gerais, v.12, n.3, p. 31-40, 2010.

Recebido em: 25/07/2017 Aprovado em: 05/03/2018

Publicado em: 31/o8/2018 